\title{
In Vitro Dissolution Enhancement of Ondansetron by Solid Dispersion in Superdisintegrants
}

\author{
Rajnikant M. Suthar ${ }^{1, *}$, Narendra P. Chotai ${ }^{1}$, Hardik K. Patel', \\ Sandip R. Patel' ${ }^{1}$, Digesh D. Shah ${ }^{2}$, and Mukesh B. Jadeja ${ }^{3}$ \\ 'Department of Pharmaceutics and Pharmaceutical Technology, Sardar Patel University, \\ A. R. College of Pharmacy P.O. Box No.-9, Vallabh Vidyanagar, Anand, Gujarat, India \\ ${ }^{2}$ Sanofi Aventis Pharmadeuticals Ltd., Ankaleshwar, Gujarat, India \\ ${ }^{3}$ Smt. S. M. Shah College of Pharmacy, Mahemdavad, Gujarat, India
}

\begin{abstract}
Ondansetron hydrochloride (OSH) is a highly selective and potent antagonist of 5-hydroxytryptamine at $5 \mathrm{HT}_{3}$ receptors in the gastrointestinal tract where it blocks both sites of serotonin induced nausea and vomiting. Physical mixtures and solid dispersions of the drug using superdisintegrants as carriers were prepared by a solvent method at different drug-carrier $(\mathrm{w} / \mathrm{w})$ ratios and evaluated with an objective of enhancing the dissolution rate of OSH from solid dispersion. Equilibrium solubility studies were performed for drug-carrier interactions in solution, and Fourier transform infrared (FTIR) spectroscopy, X-ray powder diffraction (XRD), and differential scanning calorimetry (DSC) studies were carried out to characterize the solid dispersions. FTIR spectra reveal no chemical interaction between the drug and superdisintegrants. XRD and DSC data indicate $\mathrm{OSH}$ was in the amorphous form, which explains the better dissolution rate of the drug from its solid dispersions. A marked enhancement in the dissolution of OSH was observed with all the superdisintegrants.
\end{abstract}

KEYWORDS: Ondansetron hydrochloride (OSH), superdisintegrants, solid dispersions, dissolution.

\section{INTRODUCTION}

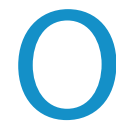
ndansetron hydrochloride (OSH) is an effective and well-tolerated antiemetic that is used for the prevention of both chemotherapy- and radiotherapy-induced emesis and nausea. OSH is sparingly soluble in water (1). It is well absorbed from the gastrointestinal tract and undergoes some first-pass metabolism. Mean bioavailability in healthy subjects following administration of a single 8-mg tablet is approximately $56 \%$.

In the case of poorly water-soluble drugs, dissolution is the rate-limiting step in the process of drug absorption. Potential bioavailability problems are prevalent with extremely hydrophobic drugs due to erratic and incomplete absorption from the gastrointestinal tract (GIT). Techniques that have commonly been used to improve dissolution and bioavailability of poorly water-soluble drugs in general include micronization, the use of surfactants, and the formation of solid dispersions (2).

The two basic procedures used to prepare solid dispersions are the fusion and cosolvent techniques. In the fusion method, a physical mixture of an active agent and a water-soluble carrier is heated until it is melted. The melt is solidified rapidly in an ice bath with vigorous stirring, pulverized, and then sieved. The solidification process can be achieved on stainless steel plates attached to a cooling system to favor rapid heat loss. Spray congealing from a modified spray drier onto a cold metal surface has also

${ }^{*}$ Corresponding author. been used. In the cosolvent technique, drug and carrier are dissolved in a common solvent, and then the solvent is evaporated under vacuum or in an oven to produce a solid dispersion $(3,4)$.

The aim of the present study was to formulate and evaluate the physicochemical properties of prepared solid dispersions of OSH in superdisintegrants. DSC, XRD, and FTIR as well as dissolution and solubility studies were performed to characterize the prepared dispersions.

\section{MATERIALS}

OSH, croscarmellose sodium (CCS), crospovidone (CP), sodium starch glycolate (SSG), and low-substituted hydroxypropyl cellulose (L-HPC) were received as gift samples from Zydus Cadila Ltd., Ahmedabad. Other reagents and organic solvents used were of analytical grade.

$\mathrm{OSH}$ is a white to off-white crystalline powder available in base and chloride salt forms. The base is sparingly soluble in water and alcohol, soluble in methanol, slightly soluble in isopropyl alcohol and dichloromethane, and very slightly soluble in acetone, chloroform, and ethyl acetate.

\section{METHODS \\ Preparation of Solid Dispersions and Physical Mixtures \\ Solid dispersions containing drug $(\mathrm{OSH})$ and excipi- ent in the proportions of 1:1,1:2, and 1:3 were prepared employing CP, L-HPC, CCS, and SSG as excipients. OSH was dissolved in alcohol to a clear solution. The OSH solution}


was then poured onto the excipient, put in a mortar, and mixed thoroughly. The wet solid mixture was dried at $60^{\circ} \mathrm{C}$ for $4 \mathrm{hr}$ in a vacuum oven (Sintex Industries, India), and the coprecipitate obtained was powdered in a mortar, passed through an 80-mesh sieve, and stored in a desiccator at room temperature for $24 \mathrm{~h}$. For the preparation of physical mixtures, OSH and excipient (CP, L-HPC, CCS, and SSG) were passed through a 100-mesh sieve and then accurately weighed in the proportions of 1:1, 1:2, and 1:3. They were mixed well in a mortar and sifted through an 80-mesh sieve.

\section{Characterization of Solid Dispersions \\ Equilibrium Solubility Studies}

The equilibrium solubilities of pure OSH powder, prepared solid dispersions, and physical mixtures in distilled water were determined at $37 \pm 0.5^{\circ} \mathrm{C}$. A known excess amount (approximately $10 \mathrm{mg}$ ) of $\mathrm{OSH}$, solid dispersion, and physical mixture (equivalent to $10 \mathrm{mg}$ of $\mathrm{OSH}$ ) were placed in sealed glass containers containing $20 \mathrm{~mL}$ of distilled water. Samples were stirred at $37 \pm 0.5^{\circ} \mathrm{C}$ on a magnetic stirrer for $48 \mathrm{~h}$. Each sample was then filtered through a $0.45-\mu \mathrm{m}$ filter. The filtrate was diluted and assayed spectrophotometrically (Shimadzu UV-1601, Shimadzu Corp, Japan) for OSH content at $310 \mathrm{~nm}$.

\section{Preparation of Standard OSH Stock Solution $(100 \mu \mathrm{g} / \mathrm{mL})$}

A 10-mg sample of OSH standard was weighed and transferred to a $100-\mathrm{mL}$ volumetric flask. Thirty milliliters of distilled water was transferred to the flask, which was then sonicated for $10 \mathrm{~min}$. The flask was shaken and brought to volume with distilled water to give a solution containing $100 \mu \mathrm{g} / \mathrm{mL}$ OSH. All solubility measurements were performed in triplicate.

\section{Fourier Transform Infrared Spectroscopy}

FTIR spectra of the pure drug, excipients, and prepared solid dispersions were obtained on a PerkinElmer 1600 FTIR spectrometer (Spectrum GX FTIR system, PerkinElmer, USA). Samples were prepared in $\mathrm{KBr}$ disks ( $2 \mathrm{mg}$ sample in $200 \mathrm{mg} \mathrm{KBr}$ ). The scanning range was $400-4000 \mathrm{~cm}^{-1}$, and the resolution was $1 \mathrm{~cm}^{-1}$.

\section{X-ray Diffraction}

XRD patterns of pure drug, superdisintegrants, and prepared solid dispersions were obtained using a powder diffractometer (Philips X'Pert MPD system) with CuK radiation. Samples were prepared by placing a thin layer of powder in conventional cavity mounts.

\section{Differential Scanning Calorimetry}

The DSC thermograms of pure drug, superdisintegrants, and solid dispersions were recorded on a DSC (PerkinElmer Instruments, Pyris-1 DSC). The samples were weighed and heated in hermetically sealed aluminum pans over a temperature range of $50-300^{\circ} \mathrm{C}$. The system was purged with nitrogen gas at a flow rate of $80 \mathrm{~mL} / \mathrm{min}$.

\section{Dissolution Studies}

Dissolution experiments were performed in triplicate using USP Apparatus 2 (Scientific USP Standards DA-60, Veego, India) in $0.1 \mathrm{~N} \mathrm{HCl}$ to simulate gastric fluid conditions at $37 \pm 0.5^{\circ} \mathrm{C}$ at a speed of $50 \mathrm{rpm}$. Powdered samples of each preparation equivalent to $8 \mathrm{mg}$ of $\mathrm{OSH}$ were added to the dissolution medium. The powder did not float on the surface. Dissolution studies were conducted for $30 \mathrm{~min}$, and 5-mL samples were collected at 5-, 10-, 15-, and 30-min intervals. The volume of dissolution fluid was adjusted to 500 $\mathrm{mL}$ by replacing each $5-\mathrm{mL}$ aliquot withdrawn with $5 \mathrm{~mL}$ of dissolution medium, pre-warmed at $37 \pm 0.5^{\circ} \mathrm{C}$. Samples withdrawn were filtered through Whatman filter paper (0.45- $\mu \mathrm{m})$, suitably diluted, and assayed for OSH by measuring absorbance at $310 \mathrm{~nm}$ using a Shimadzu UV-1601 Spectrophotometer (Shimadzu Corporation, Japan).

\section{RESULTS AND DISCUSSION \\ Solubility Measurement}

The equilibrium solubility data are presented in Table 1. The solubility of $\mathrm{OSH}$ powder in distilled water at $37 \pm 0.5^{\circ} \mathrm{C}$ was $0.724 \mathrm{mg} / \mathrm{mL}$, whereas solubilities of the solid dispersion and physical mixture were in the ranges of 3.112-7.124 $\mathrm{mg} / \mathrm{mL}$ and $1.960-4.316 \mathrm{mg} / \mathrm{mL}$, respectively (Table 1 ). These findings suggest that solid dispersions had much more enhanced equilibrium solubility (5-10-fold) as compared with pure drug powder and physical mixtures (2-6fold). The solubility in a physical mixture may be increased due to trituration of the drug with superdisintegrants in a mortar, thereby converting it to the amorphous form, and because of the solvent properties of superdisintegrants.

\section{Fourier Transform Infrared Spectroscopy}

IR spectroscopic studies of OSH powder, superdisintegrants, and some selected samples of solid dispersions were carried out to determine possible interactions of the drug with the superdisintegrants and to characterize the solid-state dispersions. Pure OSH displays a peak characteristic of the $\mathrm{NH}$ bending vibration at $1638.1 \mathrm{~cm}^{-1}$ and peaks at $1280.62 \mathrm{~cm}^{-1}$ and $760.1 \mathrm{~cm}^{-1}$, which are indicative of $\mathrm{CN}$ stretching and ortho-substituted phenyl $\mathrm{CH}$ bending, respectively. Peaks of different functional groups of $\mathrm{OSH}$ in various solid dispersions did not deviate much from peaks of pure drug except in the OSH-CP solid dispersion. IR spectra of the solid dispersions are identical to those of the corresponding pure drug and superdisintegrants. Consequently, the FTIR spectra of solid dispersions seem to be a combination of only drug and superdisintegrant spectra.

\section{X-ray Diffraction}

The powder diffraction patterns of pure OSH exhibit characteristic high-intensity diffraction peaks. The powdered superdisintegrants were amorphous, where the XRD patterns had only few peaks with very weak intensities. The crystalline structure of OSH was destroyed in all solid dispersions, 
Table 1. Equilibrium Solubility of Different Formulations of OSH Tested in Distilled Water at $37 \pm 0.5^{\circ} \mathrm{C}$

\begin{tabular}{|c|c|c|c|}
\hline \multirow{3}{*}{ Drug-Carrier Ratio } & \multicolumn{3}{|c|}{ Solubility $(\mathrm{mg} / \mathrm{mL})^{a}$} \\
\hline & \multirow{2}{*}{$\begin{array}{c}\text { Drug } \\
\text { (with or without carrier) }\end{array}$} & \multicolumn{2}{|c|}{ Formulation Type ${ }^{b}$} \\
\hline & & SD & PM \\
\hline $1: 00$ & $\mathrm{OSH}$ & \multicolumn{2}{|c|}{$0.724 \pm 0.523$} \\
\hline \multirow[t]{4}{*}{ 1:01 } & $\mathrm{OSH}+\mathrm{CP}$ & $4.012 \pm 0.812$ & $2.826 \pm 0.314$ \\
\hline & $\mathrm{OSH}+\mathrm{L}-\mathrm{HPC}$ & $3.912 \pm 0.556$ & $2.584 \pm 0.286$ \\
\hline & $\mathrm{OSH}+\mathrm{CCS}$ & $3.112 \pm 0.534$ & $1.960 \pm 0.413$ \\
\hline & $\mathrm{OSH}+\mathrm{SSG}$ & $3.564 \pm 0.242$ & $2.126 \pm 0.297$ \\
\hline \multirow[t]{4}{*}{ 1:02 } & $\mathrm{OSH}+\mathrm{CP}$ & $5.843 \pm 0.926$ & $3.424 \pm 0.527$ \\
\hline & $\mathrm{OSH}+\mathrm{L}-\mathrm{HPC}$ & $5.214 \pm 0.801$ & $3.362 \pm 0.713$ \\
\hline & $\mathrm{OSH}+\mathrm{CCS}$ & $4.384 \pm 0.612$ & $2.728 \pm 0.628$ \\
\hline & $\mathrm{OSH}+\mathrm{SSG}$ & $4.957 \pm 0.756$ & $3.287 \pm 0.345$ \\
\hline \multirow[t]{4}{*}{$1: 03$} & $\mathrm{OSH}+\mathrm{CP}$ & $7.124 \pm 0.768$ & $4.316 \pm 0.387$ \\
\hline & $\mathrm{OSH}+\mathrm{L}-\mathrm{HPC}$ & $6.646 \pm 0.996$ & $4.123 \pm 0.811$ \\
\hline & $\mathrm{OSH}+\mathrm{CCS}$ & $5.815 \pm 0.769$ & $3.815 \pm 0.765$ \\
\hline & $\mathrm{OSH}+\mathrm{SSG}$ & $6.185 \pm 0.212$ & $4.016 \pm 0.714$ \\
\hline
\end{tabular}

${ }^{a}$ Mean $\pm S D$; standard deviation $(n=3)$.

${ }^{b}$ PM: physical mixture; SD: solid dispersion.

Table 2. Cumulative Percentage OSH Released from Solid Dispersions and Physical Mixtures

\begin{tabular}{|c|c|c|c|c|c|}
\hline \multirow{2}{*}{ Formulation $^{a}$} & \multirow{2}{*}{ Ratio } & \multicolumn{4}{|c|}{ Time $(\min )^{b}$} \\
\hline & & 5 & 10 & 15 & 30 \\
\hline \multirow[t]{2}{*}{ Pure drug $(\mathrm{OSH})$} & $1: 0$ & $17.96 \pm 0.79$ & $21.20 \pm 0.109$ & $23.80 \pm 0.183$ & $31.25 \pm 0.424$ \\
\hline & $1: 1$ & $74.07 \pm 0.202$ & $77.23 \pm 0.112$ & $80.89 \pm 0.134$ & $85.51 \pm 0.097$ \\
\hline \multirow[t]{3}{*}{$\mathrm{SD}(\mathrm{OSH}+\mathrm{CP})$} & $1: 2$ & $78.30 \pm 0.115$ & $83.34 \pm 0.042$ & $85.58 \pm 0.166$ & $91.31 \pm 0.053$ \\
\hline & $1: 3$ & $82.23 \pm 0.203$ & $86.44 \pm 0.046$ & $90.37 \pm 0.203$ & $97.11 \pm 0.126$ \\
\hline & $1: 1$ & $68.60 \pm 0.253$ & $71.86 \pm 0.07$ & $74.32 \pm 0.141$ & $79.34 \pm 0.139$ \\
\hline \multirow[t]{3}{*}{$\mathrm{SD}(\mathrm{OSH}+\mathrm{L}-\mathrm{HPC})$} & $1: 2$ & $71.03 \pm 0.111$ & $74.53 \pm 0.038$ & $77.65 \pm 0.111$ & $84.54 \pm 1.136$ \\
\hline & $1: 3$ & $80.75 \pm 0.095$ & $82.34 \pm 0.056$ & $84.45 \pm 0.124$ & $90.91 \pm 0.175$ \\
\hline & $1: 1$ & $60.71 \pm 0.097$ & $63.74 \pm 0.211$ & $67.05 \pm 0.428$ & $72.50 \pm 0.093$ \\
\hline \multirow[t]{3}{*}{$\mathrm{SD}(\mathrm{OSH}+\mathrm{CCS})$} & $1: 2$ & $64.87 \pm 0.094$ & $68.60 \pm 0.078$ & $70.19 \pm 0.083$ & $75.01 \pm 0.036$ \\
\hline & $1: 3$ & $72.40 \pm 0.097$ & $75.46 \pm 0.079$ & $78.57 \pm 0.084$ & $84.43 \pm 0.131$ \\
\hline & $1: 1$ & $63.60 \pm 0.245$ & $66.78 \pm 0.078$ & $69.56 \pm 0.134$ & $75.33 \pm 0.114$ \\
\hline \multirow[t]{2}{*}{$\mathrm{SD}(\mathrm{OSH}+\mathrm{SSG})$} & $1: 2$ & $67.03 \pm 0.056$ & $70.45 \pm 0.045$ & $74.56 \pm 0.134$ & $80.45 \pm 0.067$ \\
\hline & $1: 3$ & $78.67 \pm 0.086$ & $80.98 \pm 0.143$ & $82.56 \pm 0.098$ & $87.43 \pm 0.026$ \\
\hline $\mathrm{PM}(\mathrm{OSH}+\mathrm{CP})$ & \multirow{4}{*}{$1: 3$} & $40.92 \pm 0.204$ & $42.09 \pm 0.140$ & $45.51 \pm 0.180$ & $52.12 \pm 0.145$ \\
\hline $\mathrm{PM}(\mathrm{OSH}+\mathrm{L}-\mathrm{HPC})$ & & $38.22 \pm 0.102$ & $41.50 \pm 0.139$ & $46.33 \pm 0.090$ & $50.05 \pm 0.170$ \\
\hline $\mathrm{PM}(\mathrm{OSH}+\mathrm{CCS})$ & & $34.40 \pm 0.155$ & $40.20 \pm 0.146$ & $43.50 \pm 0.040$ & $46.69 \pm 0.098$ \\
\hline $\mathrm{PM}(\mathrm{OSH}+\mathrm{SSG})$ & & $37.13 \pm 0.247$ & $42.00 \pm 0.132$ & $44.41 \pm 0.221$ & $49.13 \pm 0.167$ \\
\hline
\end{tabular}

a $P M$, physical mixture; $S D$, solid dispersion.

${ }^{b}$ Mean $\pm S D$; standard deviation $(n=3)$. 


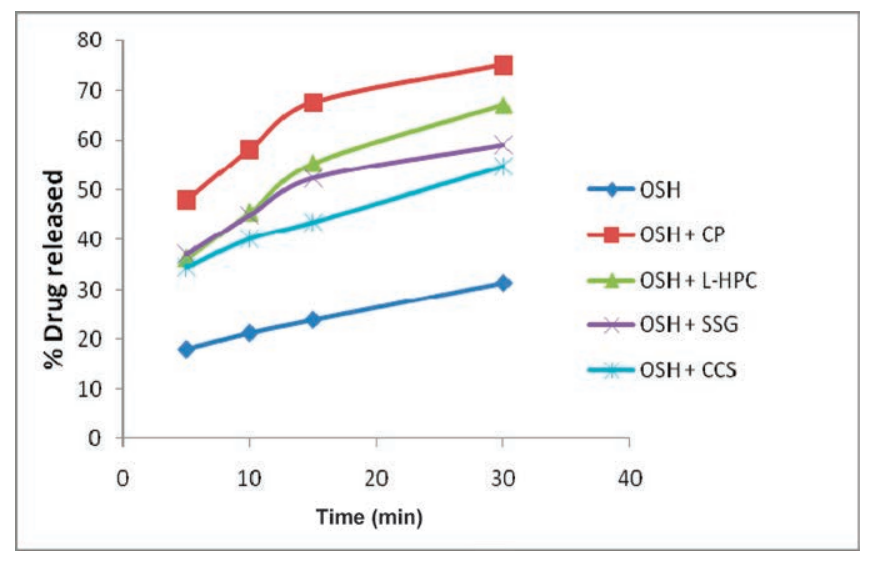

Figure 1. Comparative release profiles of pure OSH and PM formulations in a 1:3 ratio.

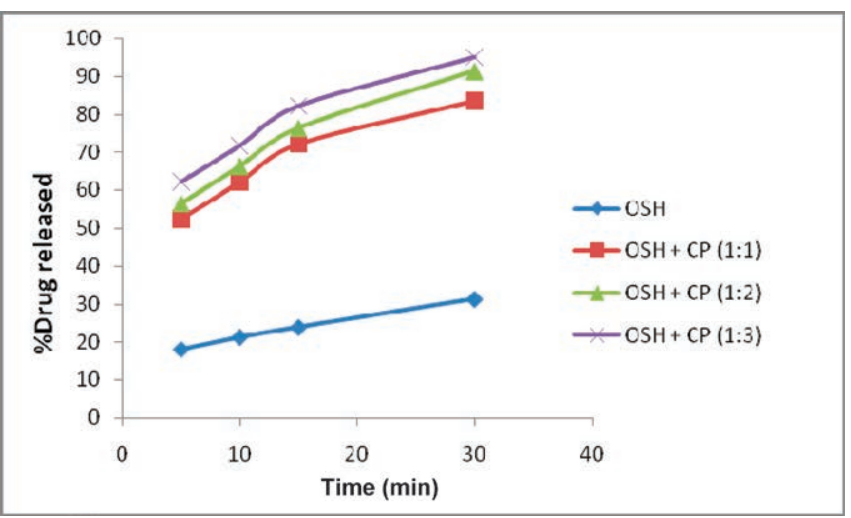

Figure 2. Cumulative percentage drug released from $\mathrm{OSH}-\mathrm{CP}$ solid dispersions.

which is evident from the decrease in the number and intensity of peaks in all solid dispersions. Thus, the crystalline structure of OSH was converted to the amorphous form in solid dispersions and physical mixtures.

\section{Differential Scanning Calorimetry}

The DSC thermogram of OSH exhibits an endothermic peak at $186.707^{\circ} \mathrm{C}$, which corresponds to its melting point. Solid dispersions of OSH in various superdisintegrants also gave melting peaks but at slightly lower temperatures in the range of $174-185^{\circ} \mathrm{C}$ with a decrease in peak intensity as compared with pure OSH. This is consistent with a weak endothermic reaction between OSH and superdisintegrants. The decrease in intensity and broadening of peak of OSH was observed in all solid dispersion formulations.

\section{Dissolution Study}

The results of the dissolution studies of pure drug, solid dispersions, and physical mixtures are shown in Table 2.

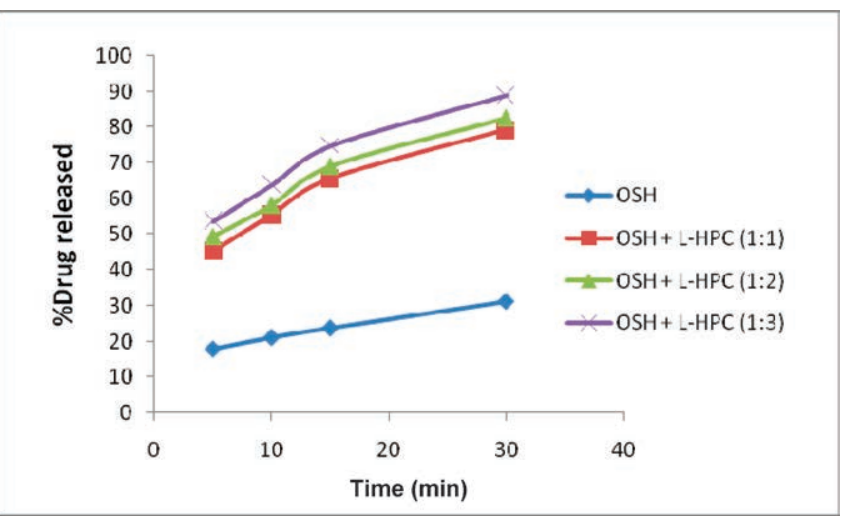

Figure 3. Cumulative percentage drug released from OSH-L-HPC solid dispersions.

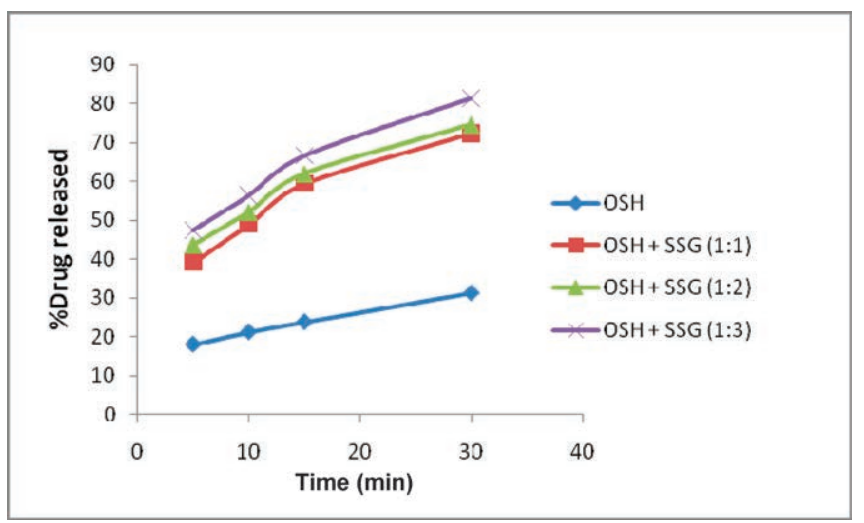

Figure 4. Cumulative percentage drug released from OSH-SSG solid dispersions.

The percentage of drug dissolved from solid dispersions within 30 min was $98 \%$ compared with only $30 \%$ for the pure drug and $74 \%$ for physical mixtures. Solid dispersions exhibited about a 3.5 -fold increase in dissolution compared with the pure drug. The dissolution rate was increased by increasing the proportion of superdisintegrants in the physical mixtures (Figure 1) and solid dispersions from 1:1 to 1:3 (Figures 2-5). The rank order of the superdisintegrants to enhance the dissolution rate is CP > L-HPC > SSG > CCS (Table 2). The dissolution study revealed that the OSH-CP (1:3) solid dispersion system had the maximum dissolution rate $(98 \%$ release within 30 min) followed by the OSH-L-HPC (1:3) system, OSH-SSG (1:3) system, and finally the OSH-CCS (1:3) system (Figure 6). The mechanisms by which superdisintegrants enhance drug dissolution are not yet well understood. However, factors such as improved wettability, increased surface area, loss of crystalline structure of drug, and solubilization effects associated with the carrier are probably responsible for their effect. 


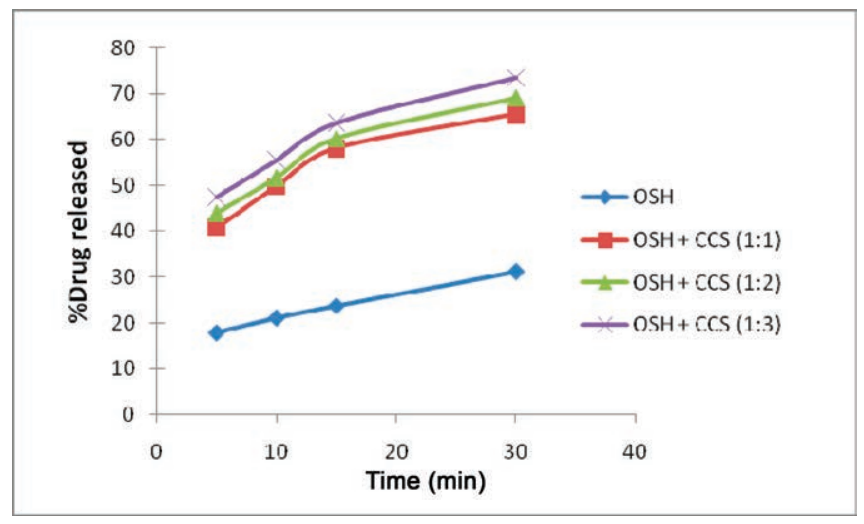

Figure 5. Cumulative percentage drug released from $\mathrm{OSH}-\mathrm{CCS}$ solid dispersions.

\section{ACKNOWLEDGMENTS}

The authors take this opportunity to thank Zydus Cadila Ltd., Ahmedabad,India, and Relax Pharmaceuticals Ltd., Vadodara, India, for providing gift samples of drug and excipients.

\section{REFERENCES}

1. Salem, I. I.; Ramos Lopez, J. M.; Galan, A. C. Ondansetron Hydrochloride. In Analytical Profiles of Drug Substances and Excipients; Brittan, H. G., Ed.; Academic Press: San Diego, CA, 2001; Vol. 27, pp 301-318.

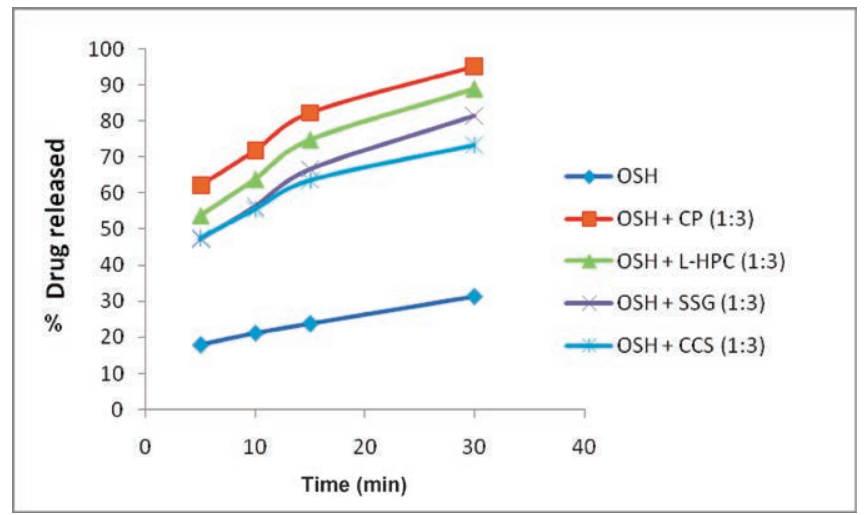

Figure 6. Comparative release profiles of pure OSH and SD formulations in a 1:3 ratio.

2. Chiou, W. L.; Riegelman, S. Pharmaceutical applications of solid dispersion systems. J. Pharm. Sci. 1971, 60 (9), 1281-1302. DOI: 10.1002/jps.2600600902.

3. Sammour, O. A.; Hammad, M. A.; Megrab, N. A.; Zidan, A. S. Formulation and optimization of mouth dissolve tablets containing rofecoxib solid dispersion. AAPS PharmSciTech 2006, 7 (2), E167-E175. DOI: 10.1208/ pt070255.

4. Valleri, M.; Mura, P.; Maestrelli, F.; Cirri, M.; Ballerini, R. Development and evaluation of glyburide fast dissolving tablets using solid dispersion technique. Drug Dev. Ind. Pharm. 2004, 30 (5), 525-534. DOI: 10.1208/ s12249-008-9066-4. 